This deplorable state of affairs, which is a cause of much wasted time and many unnecessary $x$-ray examinations, can be directly related to the very severe reduction in the amount of time which our medical schools allocate to the teaching and study of anatomy. In practical terms, it means that students become involved with contemplation of the abnormal before they have acquired a sound knowledge of the normal.

Perhaps the tide is now beginning to turn, for, during the past year or so, there have been at least three publications affirming the importance of teaching radiological anatomy from the outset of the preclinical course. Can this really be just a coincidence?

KENNETH SWINBURNE

Wharfedale General Hospital,

' Keats, T E, Atlas of Normal Roentgen Variants. Chicago, Year Book Medical Publishers, 1973. 'Swinburne, K, Lancet, 1978, 1, 433.

Golberg, B, British Medical fournal, 1978, 1, 1017.

4 Reidy, J, et al, Clinical Radiology, 1978, 29, 591.

SIR,- - The 28 specialties listed in the survey by Professor V Wright and others $(24$ March, p 805) would obviously relate very much to what medical practitioners had themselves learned in medical school. To us it was most striking, but not surprising, that no mention was made of nutrition at all, except to suggest metaphorically that medical students know what they enjoy academically, but not necessarily what is good for them: "The student knows what is palatable, but not always what is nutritious." Ironically, this is literally the situation in practice for those graduating with the curricular emphases suggested in this present study.

The absurd paradox of not including such a universal subject as nutrition in the curriculum is highlighted most clearly by current correspondence in the same issue ( $\mathrm{p} \mathrm{818}$ ) concerning "Prescription for a better British diet." How, one may ask, can the medical profession make the slightest informed input into these decisions if they have no knowledge because of an almost complete lacuna in their training ? More importantly still, how can they advise their patients appropriately?

D B JELLIFFE E F PATRICE JELLIFFE

Division of Population, Family, and International Health, University School of Public Health, Los Angeles,

California 90024, USA

\section{Breast cancer in young women}

SIR,-I was interested in your leading article on age and death in breast cancer (27 January, p 211). I would like to present further data supporting the thesis that breast cancer in young women is less aggressive than is currently believed.

Twenty-seven women (27-45 years old) were treated by modified radical mastectomy and those with large tumours and extramammary spread also received radiotherapy with or without chemotherapy and oophorectomy. The lymph nodes, all containing macrometastases, were not grouped by levels, the value of which is now in doubt. ${ }^{1}$ Of these 27 patients, 20 had moderately welldifferentiated carcinomas, two infiltrating comedocarcinomas, two invasive lobular carcinomas, and one a medullary carcinoma

I have no similar data on my older patients and for comparison I have used figures given in the literature for short-term treatment failure and five-year survival rate. It is clear that, despite adverse prognostic factors, ${ }^{1-3}$ these patients have done surprisingly well. The quoted incidence rate of short-term treatment failure at 12,18 , and 24 months is $12 \cdot 2 \%, 21 \cdot 2 \%$, and $41 \cdot 2 \%$ respectively ${ }^{2}$; of my 27 patients, only one died 11 months after surgery. The overall five-year survival rate ranges from $46^{\circ}$ to $65^{\circ}{ }_{0}^{3}$; only one of my 15 patients followed up for over five years has so far died of breast cancer $\left(93.3^{\circ}{ }_{0}\right.$ five-year survival rate).

These figures, though based on a small series, justify optimism and I feel that physicians should judiciously inform the public of this "good news." It may help to break through the fear barrier and lead young women to examine their breasts more regularly and report early any abnormal findings. Earlier diagnosis can only improve their chances of survival.

H HONORÉ

Memorial University of Newfoundland,

Grace General Hospital,

${ }^{1}$ Fisher, E R, et al, Cancer, 1978, 42, 2032.

2 Fisher, E R, Gregorio, R M, and Fisher, B, Cancer 1975, 36,

Diekamp, U, Bitran, J, and Ferguson, D J, fournal of Reproductive Medicine, 1976, 5, 255.

\section{Hypnosis}

SIR,-I was most interested in your correspondents' reactions to my submission that the hypnosis lobby has not yet conclusively proved its case.

Regarding Dr H K Gooding's comments (14 April, p 1017), of course Dr D Waxman (19 August, 1978, p 571) uses the method responsibly; but will all the others attracted to this still esoteric therapeutic technique? Again, Dr Gooding's rapport with his smoking patient is obviously of excellent placebo value at least. Is there any more to it? He himself is, of course, not obliged to conduct controlled trials with individual patients (though the simple mirror-image trial, using the patient as his own control, is always open to him); but he should always remember that spectacular "results" may not be due to the treatment given.

Dr Gooding refers to the studies of Dr G P Maher-Loughnan as proving the efficacy of the hypnotic approach. However, the latter's first paper $^{1}$ describing a controlled trial of hypnosis in the symptomatic treatment of asthma admits that his finding of its value "is based purely on a subjective assessment, and there remain many questions to be solved concerning satisfactory objective methods of assessment." There do indeed. When objective methods-that is, lung function tests-were included in a later, much larger, controlled trial, ${ }^{2}$ the results of these were the same in the experimental and control groups, suggesting that hypnosis does not exert a physiological effect, that any improvement is a subjective, placebo one. Even with regard to the various subjective assessments used, while independent clinical assessors did find the asthma much better in more of the hypnosis group $(59 \%$ as against $43 \%$ in the controls, not a huge advantage), there was no difference (for males) in the scores for wheezing or bronchodilator use. Females differed, for some obscure reason. If, then, this is the definitive trial of the value of hypnosis in a classically psychosomatic (so-called) condition such as asthma, to my mind the point is not proved beyond doubt. Moreover, the very first controlled study ${ }^{3}$ showed that hypnotic suggestion failed to produce any improvement in 25 asthmatic children.

Dr E W Rees (14 April, p 1018) in his first paragraph appears to discount the value of scientific evidence, yet goes on to emphasise the value of the "evidence" in favour of hypnosis. Again, he (and also Dr Waxman-19 May, $p$ 1354) seems to link hypnosis with psychotherapy. This is surely. unfortunate in view of the grave doubts of many about the scientific status of psychotherapy, not to mention its potential negative effects. ${ }^{45}$

The comments of Dr P G F Nixon and Dr G D K Flint (5 May, p 1212) are helpful and interesting, but miss my main points. Of course, any doctor or dentist may practise hypnosis if he finds it useful, just as he may employ acupuncture, transcendental meditation, or any other paramedical technique; but to suggest that resources should be poured into their widespread application before their value has been firmly ascertained is, in my opinion, unjustified. The controlled trials that have been done do not show a convincing superiority for hypnosis over waking suggestion or other simple placebo techniques such as breathing exercises.

Finally, with regard to the importance of suggestion in this area, may I refer your correspondents to the current analogous controversy in your columns about the value of the "fringe" technique of homoeopathy, in particular Dr R S Walker's opinion (28 April, p 1147) that its practitioners appear to have surprisingly little insight into the powers of suggestion?

H G KINNELL

University Department of Psychological

Medicine

Newcastle General Hospital,

Newcastle upon Tyne NE4 6BE

${ }^{1}$ Maher-Loughnan, G P, et al, British Medical fournal, 1962, 2, 371 .

British Tuberculosis Association, British Medical Fournal, 1968, 4, 71.

${ }^{3}$ Burns, C L C, and Morrison Smith, J, British fournal of Diseases of the Chest, 1960, 54,78.

Rachman, S, The Effects of Psychotherapy. Oxford,

Pergamon Press, 1971.

\section{Oestrogen-induced hypocalcaemia in hypoparathyroidism}

SIR,-I read with great interest the fascinating observation of a case of hypoparathyroidism whose symptoms and biological features were aggravated by the administration of oestrogens, as reported by Drs D Verbeelen and $M$ Fuss (24 February, p 522).

This is reminiscent of the observations reported more than three decades ago by Klotz and Barbier, ${ }^{1}$ who demonstrated this phenomenon up to four times in one of their hypoparathyroid patients. One decade therefore before the introduction of sodium EDTA as a calcium-lowering agent a test of sudden hypocalcaemia was devised, using oestradiol benzoate $20 \mathrm{mg}$ intramuscularly or subcutaneously ${ }^{2}{ }^{3}$ to evaluate parathyroid reserve. The degree and the duration of the hypocalcaemia were proportional to the severity of the hypoparathyroid state. Experimental support for this oestrogen-induced hypocalcaemia had been provided by the work performed in Liège by Mathieu and coworkers ${ }^{4}$ in parathyroidectomised dogs. 